\section{Determining Exercise Intensities of Gardening Tasks as a Physical Activity Using Metabolic Equivalents in Older Adults}

\author{
Sin-Ae Park \\ Department of Environmental Sciences, Konkuk University, Seoul 143-701, \\ Korea
}

Kwan-Suk Lee

Department of Industrial Engineering, Hongik University, Seoul 121-791, Korea

\author{
Ki-Cheol Son ${ }^{1}$ \\ Department of Environmental Sciences, Konkuk University, Seoul 143-701, \\ Korea
}

Additional index words. metabolic cost, energy expenditure, Cosmed $\mathrm{K}_{4} \mathrm{~b}^{2}$, human issues in horticulture, horticultural therapy

\begin{abstract}
The objective of this study was to determine the exercise intensities of 15 gardening tasks in older adults using a portable indirect calorimeter. Twenty older Korean adults (16 females, four males) older than 65 years of age (average $67.3 \pm \mathbf{2 . 7}$ years) were recruited from the community of Gwangjin-gu, Seoul, South Korea. The subjects visited a garden created for the study at Konkuk University, Seoul, South Korea, three times and performed a total 15 gardening tasks. Subjects wore a portable calorimetric monitoring system $\left(\mathrm{Cosmed} \mathrm{K} \mathrm{b}^{2}\right)$ with telemetry that allowed measurement of oxygen consumption as they conducted each gardening task over a 5-min period and during a subsequent 5-min rest period while seated on a chair between each task. Their heart rate was also continuously measured using radiotelemetry (Polar $T$ 31) during the test. The gardening tasks performed were of low to moderate intensity physical activities [1.7-4.5 metabolic equivalents (METs)]. Tasks using both upper and lower body (e.g., digging, fertilizing, weeding, raking, tying plants to stakes) required moderate-intensity physical activity (3-4.5 METs); those using the upper body while standing or squatting (e.g., pruning, mixing soil, planting seedlings, sowing, watering using a watering can or hose, harvesting) were low-intensity physical activities (1.7-2.9 METs); and tasks requiring limited use of the upper body while standing (e.g., filling containers with soil, washing harvested produce) were the least demanding physical activities of the gardening tasks tested. The results will allow more precise tailoring of gardening activities of older individuals to achieve appropriate levels of activity for good health.
\end{abstract}

Physical activity is any bodily movement produced by the contraction of skeletal muscle that results in energy expenditure and includes a broad range of daily activities such as housework and walking for transportation (Caspersen et al., 1985). The health benefits of physical activities in older adults are significant and have been reported to prevent or reduce chronic diseases such as hypertension,

Received for publication 14 Sept. 2011. Accepted for publication 25 Oct. 2011.

This article was supported by funding from Konkuk University in 2011.

We are grateful to Dr. Stanley J. Kays, Professor, Department of Horticulture, Plant Sciences Building, University of Georgia, for his critical review of the manuscript.

${ }^{1}$ To whom reprint requests should be addressed; e-mailkcson3744@hotmail.com. of physical activities in relation to the resting metabolic rate (Ainsworth et al., 2000). METs are expressed in terms of oxygen consumption per unit body mass ( 1 MET equals to $3.5 \mathrm{ml} \mathrm{O} / \mathrm{kg} / \mathrm{min}$ ) and a resting metabolic rate such as when lying down or sitting quietly represents 1 MET (Norton et al., 2010). Physical activities are categorized as light (less than 3 METs), moderate (3 to 6 METs), and vigorous (greater than 6 METs) in itensity (Pate et al., 1995). For example, Ainsworth et al. (2011) classified walking for pleasure as a moderate-intensity physical activity (3.5 METs) and tennis as a vigorousintensity physical activity (7.3 METs) in adults. Fifty-three common lawn and garden tasks were found to be low- to moderateintensity physical activities in adults ranging in age from 25 to 65 years based on published sources or estimates by experts on physical activity (Ainsworth et al., 2011). The compendium of physical activities by Ainsworth et al. (2011), however, does not include a number of common gardening tasks and is limited to adults 65 years of age or younger.

Park et al. (2008b) determined that nine gardening tasks were low- to moderateintensity physical activity (1.6-3.6 METs) in older American adults older than 65 years in age (mean age, 77 years). Gardening tasks that used both the upper and lower body such as digging were moderate-intensity physical activities (3.6 $\pm 0.8 \mathrm{METs})$, whereas tasks that primarily used the upper body such as mixing soil were found to be low-intensity physical activities $(2.2 \pm 0.6 \mathrm{METs})$.

To determine the METs values of a physical activity, the amount of oxygen $\left(\mathrm{VO}_{2}\right)$ used during the activity is measured. Either direct or indirect calorimetry can be used to measure oxygen intake, although indirect calorimetry is more commonly used in that it is simpler and less expensive (McArdle et al., 2007). The "Douglas bag method" is generally considered to be the most accurate means of indirect calorimetry; however, it is impractical outside a clinical or research laboratory setting. Therefore, a multistepped approach was used to determine the exercise intensities of gardening tasks in previous studies (Park et al., 2008a, 2008b, 2008c). The Cosmed K4b ${ }^{2}$ (COSMED, Rome, Italy) is a portable system used to measure the energy cost of free movements that is convenient to use outdoors for measuring gardening tasks and it has the validity and accuracy equal to the Douglas bag method (Kawakami et al., 1992). Doyon et al. (2001) and McLaughlin et al. (2001) demonstrated that the Cosmed $\mathrm{K}_{4} \mathrm{~b}^{2}$ was acceptable for measuring oxygen uptake over a fairly wide range of exercise intensities.

The objective of this study was to determine the exercise intensities of adults ( 65 years of age or older) doing 15 common gardening tasks by using a portable system (Cosmed $\mathrm{K} 4 \mathrm{~b}^{2}$ ) to measure the energy cost that has high validity and accuracy. The results will facilitate tailoring garden activities of older Koreans to achieve appropriate levels of physical activity for good health. 


\section{Materials and Methods}

Subjects. Koreans older than 65 years of age were recruited from the community of Gwangjin-gu in Seoul, South Korea, using a flyer with a description of the study and registration forms that were distributed at senior centers and directly to individuals. Criteria for participation were older than 65 years in age, the absence of an uncontrolled chronic disease, heart, or lung diseases and a pacemaker, and they did not smoke. A total of 20 adults older than 65 years in age were selected based on the inclusion criteria. During orientation, a written informed consent form was obtained after the experimental procedures and schedules were provided. Subjects were required to not consume caffeine or alcohol, eat a heavy meal, and do physical activity at least $12 \mathrm{~h}$ before the test. The subjects were also required to wear clothes and shoes appropriate for gardening. At the completion of the study, each subject received U.S. \$60 as an incentive.

The following descriptive information was obtained for each of the subjects: height, weight, body composition [body mass index, fat $(\mathrm{g})$, lean $(\mathrm{g})$, and percent fat $(\%)]$, resting metabolic rate, resting heart rate, and age- adjusted maximum heart rate. Height and weight were measured using an electronic instrument (Model GL-150; G-Tech International, Uijeongbu-si, Gyeonggi-do, South Korea) and body mass index was calculated as: body mass index $=$ weight $(\mathrm{kg}) /[$ height $(\mathrm{m})]^{2}$. Fat $(\mathrm{g})$, lean $(\mathrm{g})$, and percent fat $(\%)$ were measured using dual-energy $\mathrm{x}$-ray absorptionmetry (Model Discovery-W; Hologic, Bedford, MA) by a trained specialist at Konkuk University Medical Center. Resting metabolic rate and resting heart rate were measured after the subjects sat in a chair for $5 \mathrm{~min}$ before starting the first of 15 gardening tasks.

Procedures. Forty garden plots (each $1 \mathrm{~m} \times$ $1.8 \mathrm{~m})$ at Konkuk University, Seoul, South Korea, were created for the study with two plots for each subject. A $5 \mathrm{~m} \times 9 \mathrm{~m}$ garden plot with ripe vegetables was also prepared. In addition, a grassy area with weeds for weeding and shrubs for pruning were located near the garden plots.

Fifteen gardening tasks were performed by the subjects during June 2011. The mean outside temperature was $30 \pm 4{ }^{\circ} \mathrm{C}$ during the test determined using a temperature probe (HR-TEMP) that is part of the Cosmed $\mathrm{K} 4 \mathrm{~b}^{2}$ instrument. Descriptions of the 15 gardening tasks performed by the subjects are in Table 1 .
The subjects visited the garden three times to complete the study and performed five gardening tasks for each time (Fig. 1). During the first visit, the tasks were hand weeding, digging, pruning, mixing soil, and filling containers with soil. Tasks during the second visit tasks were fertilizing, raking, planting transplants, tying plants to stakes, and watering (using a watering can) and for the third visit, sowing, mulching, watering (using a hose), harvesting, and washing the harvested produce.

Subjects did each gardening task for $5 \mathrm{~min}$ followed by a 5 -min rest period sitting in a chair between each task. In our preliminary study, 5 min was found to be sufficient for determining the exercise intensity of gardening tasks and a subsequent $5 \mathrm{~min}$ for the heart to return to its resting rate between tasks. The garden plots were the appropriate size to allow completion of each task within 5 min. During the 5-min rest period between tasks, the subjects were asked to not speak or move and the researcher demonstrated the next task. The order of the tasks was the same for all subjects and was designed to reflect typical home gardening activities and to combine moderateand low-intensity gardening tasks based on preliminary research (Park et al., 2008b).

Table 1. Descriptions of gardening tasks performed to determine the exercise intensities for each older Korean adult.

\begin{tabular}{|c|c|}
\hline Gardening tasks & Description \\
\hline Hand weeding & $\begin{array}{l}\text { Bending or squatting in a grassy area and weeding using a hand fork }(0.3 \mathrm{~kg}) \text {; some movement required } \\
\text { when they finished an area }\end{array}$ \\
\hline Digging & Digging a $1 \mathrm{~m} \times 1.8 \mathrm{~m}$ garden plot with a shovel $(1.3 \mathrm{~kg})$ \\
\hline Pruning & Pruning shrubs with hand pruning shears $(0.2 \mathrm{~kg})$; some movement required when they finished a shrub \\
\hline Mixing soil & $\begin{array}{l}\text { Mixing soil in a bucket (diameter } 66 \mathrm{~cm} \text {, height } 20 \mathrm{~cm}) \text { by hand with water added from a watering can }(3 \mathrm{~kg}) \text {, } \\
\text { performed while the bucket was standing on a } 1.8 \mathrm{~m} \times 0.6 \mathrm{~m} \times 0.8 \mathrm{~m} \text { table }\end{array}$ \\
\hline Filling containers with soil & $\begin{array}{l}\text { Filling } 10-\mathrm{cm} \text { pots with soil from a bucket (diameter } 66 \mathrm{~cm} \text {, height } 20 \mathrm{~cm} \text { ) by hand, performed while the bucket } \\
\text { was standing on a } 1.8 \mathrm{~m} \times 0.6 \mathrm{~m} \times 0.8 \mathrm{~m} \text { table }\end{array}$ \\
\hline Fertilizing & $\begin{array}{l}\text { Spreading fertilizer from a bucket with a shovel }(1.3 \mathrm{~kg}) \text { on a } 1 \mathrm{~m} \times 1.8 \mathrm{~m} \text { garden plot and mixing it into the soil } \\
\text { using a shovel }\end{array}$ \\
\hline Raking & Raking a $1 \mathrm{~m} \times 1.8 \mathrm{~m}$ garden plot with a hand rake $(0.9 \mathrm{~kg})$ \\
\hline Planting transplants & Transplanting tomato and lettuce plants into a $1 \mathrm{~m} \times 1.8 \mathrm{~m}$ garden plot using a hand trowel $(0.1 \mathrm{~kg})$ \\
\hline Tying plants to stakes & Tying tomato plants to stakes $(0.5 \mathrm{~kg})$ for support \\
\hline Sowing seed & Digging a row with a hand trowel $(0.1 \mathrm{~kg})$, sowing seed and covering them with soil \\
\hline Mulching & Applying mulch around tomato and lettuce plants in a $1 \mathrm{~m} \times 1.8 \mathrm{~m}$ garden plot \\
\hline Watering (watering can) & Watering garden plots $(4 \mathrm{~m} \times 7.2 \mathrm{~m})$ using a watering can with $6 \mathrm{~kg}$ of water \\
\hline Watering (hose) & Watering the garden plots $(4 \mathrm{~m} \times 7.2 \mathrm{~m})$ using a hose \\
\hline Harvesting produce & Harvesting produce (lettuce, tomatoes, peppers, and eggplants) from a garden plot $(5 \mathrm{~m} \times 9 \mathrm{~m})$ \\
\hline Washing produce & $\begin{array}{l}\text { Squatting near the garden and washing harvested produce using a small bucket (diameter } 30 \mathrm{~cm} \text {, height } 15 \mathrm{~cm} \text { ) } \\
\text { and a water hose. }\end{array}$ \\
\hline
\end{tabular}

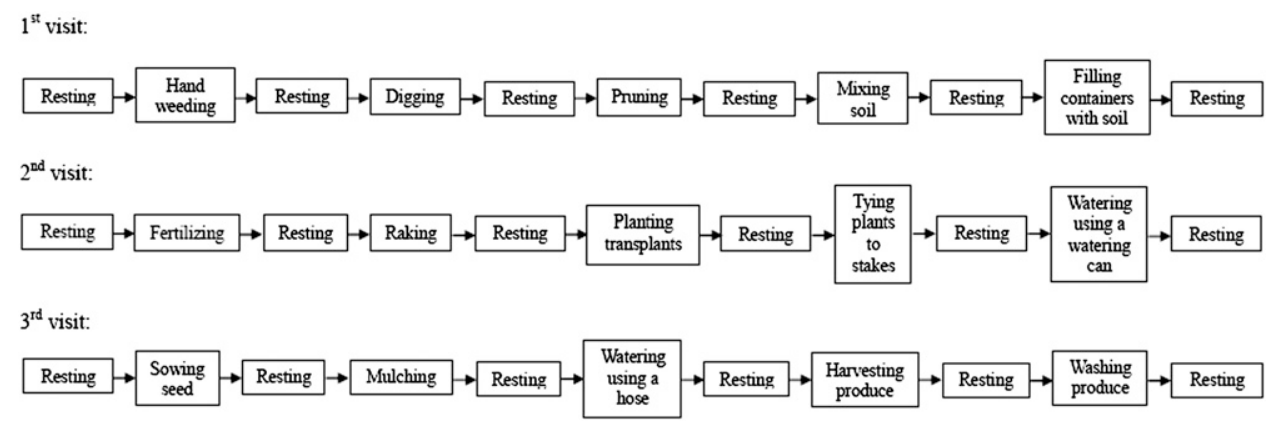

Fig. 1. Sequence of gardening tasks performed by older Korean adults to determine the exercise intensity required. Subjects did each task for 5 min and then spent 5 min resting while sitting in a chair between tasks. The order of the gardening tasks was the same for all subjects. Based on preliminary work (Park et al., 2008b), the sequence combined moderate and low intensity tasks. 
Metabolic measurement. Each subject wore a portable Cosmed $\mathrm{K}_{4} \mathrm{~b}^{2}$ during the gardening tasks that included a portable telemetric transmitter, facemask, flow meter, gas analyzer, receiver, and temperature probe (HR-TEMP). The instrument weighed $1.5 \mathrm{~kg}$ with the battery and specially designed harness. Each subject continuously respired into the facemask, which allowed measuring their $\mathrm{VO}_{2}$ during the active and rest periods.

Before starting the tests, oxygen and carroom air and with a reference gas containing $15.93 \%$ oxygen and $4.92 \%$ carbon dioxide. a 3.0-L syringe followed by a delay calibration to adjust for the lag time between the expiratory flow measurement and the gas analysis.

The subject's heart rate was continuously monitored throughout their test period using registered in the Cosmed $\mathrm{K} 4 \mathrm{~b}^{2}$ using radiotelemetry (Polar T 31; FitMed, Kempele, Finland).

Data analysis. Descriptive information was handled using Excel (Microsoft Office 2002; Microsoft Corp., Redmond, WA). Each subject's physiological data were collected continually using the Cosmed $\mathrm{K} 4 \mathrm{~b}^{2}$ with individual points representing averaged 3 -s intervals. For each gardening task, data for the first and last $10 \mathrm{~s}$ were deleted to compensate for the time required to walk to their garden plot before starting a task or returned to the chair for the rest period. Duncan's multiple means of metabolic rates for the 15 gardening tasks calculated using the Statistical Analysis System (SAS Version 9 for Windows; SAS Institute Inc., Cary, NC).

\section{Results}

Characteristics of the subjects. The descriptive characteristics of the subjects participating in the study are presented in Table 2. The mean age of the 20 subjects ( 16 female, four male) was $67.3 \pm 2.7$ years. The average body mass index of the subjects was normal bon dioxide analyzers were calibrated with The flow turbine was then calibrated using a monitor on the skin under the breast and range test at $P<0.05$ was used to compare

to overweight (body mass index $26.4 \pm 3.6$ $\left.\mathrm{kg} / \mathrm{m}^{2}\right)$.

Exercise intensity of gardening tasks. Subjects' heart rate and $\mathrm{VO}_{2}$ were significantly increased during the each garden task (Table 3). The garden tasks also induced energy expenditure of older participants.

The 15 gardening tasks performed by the participants represented low- to moderateintensity physical activities (Table 3 ). Digging (mean $4.5 \pm 1.2)$, fertilizing $(4.0 \pm 0.9)$, raking $(3.4 \pm 0.8)$, weeding $(3.4 \pm 0.6)$, mulching $(3.3 \pm 0.8)$, and tying plants to stakes $(3.0 \pm 1.0)$ were moderate-intensity physical activity (i.e., 3-4.5 METs). Planting seedlings (mean $2.9 \pm 0.9$ ), watering using a watering can $(2.8 \pm 0.9)$, sowing $(2.7 \pm 0.6)$, harvesting $(2.7 \pm 0.6)$, mixing soil $(2.4 \pm 0.7)$, pruning $(2.5 \pm 0.7)$, watering using a hose $(2.4 \pm 0.8)$, and washing harvested produce (mean $1.7 \pm 0.4$ ) were low-intensity physical activities (i.e., 1.7-2.9 METs). Digging and fertilizing were more intense than the other gardening tasks $(P<0.05)$. Filling containers with soil and washing harvested produce were lower intense tasks than the 15 gardening tasks $(P<0.05)$.

\section{Discussion}

The 15 gardening tasks performed by adults older than 65 years in age (mean age, $67.3 \pm 2.7$ years; mean body mass index, $26.4 \pm$ $3.6 \mathrm{~kg} / \mathrm{m}^{2}$ ) were determined to be low- to moderate-intensity physical activities $(1.7 \pm$ 4.5 METs).

The gardening tasks that used both upper and lower body such as digging, fertilizing, weeding, raking, and tying plants to stakes were moderate-intensity physical activity (34.5 METs). The gardening tasks that used actively upper body while standing (sometimes slight walking for moving when they finished an area) or squatting such as pruning, mixing soil, planting seedlings, sowing, watering (by watering can or hose), and harvesting were low-intensity physical activity (1.7-2.9 METs). Meanwhile, the tasks such as filling a container with soil and washing harvests slightly used the

Table 2. Descriptive information for older Koreans $(n=20)$ participating in the study to determine the exercise intensity of gardening tasks.

\begin{tabular}{|c|c|c|}
\hline Variable & Mean & SD \\
\hline Age (years) & 67.3 & 2.7 \\
\hline Height $(\mathrm{cm})$ & 154.2 & 6.4 \\
\hline Body weight (kg) & 62.9 & 9.9 \\
\hline \multicolumn{3}{|l|}{ Body composition } \\
\hline Body mass index $\left(\mathrm{kg} \cdot \mathrm{m}^{-2}\right)$ & 26.4 & 3.6 \\
\hline Fat $(g)^{\mathrm{z}}$ & $19,739.5$ & $7,621.6$ \\
\hline Lean $(g)^{\mathrm{z}}$ & $37,939.2$ & $9,855.1$ \\
\hline Percent fat $(\%)^{\mathrm{z}}$ & 32.2 & 7.4 \\
\hline \multicolumn{3}{|l|}{ Resting metabolic rate ${ }^{y}$} \\
\hline $\mathrm{VO}_{2}\left(\mathrm{~mL} \cdot \mathrm{kg}^{-1} \cdot \mathrm{min}^{-1}\right)$ & 3.8 & 0.9 \\
\hline $\mathrm{kj} \cdot \mathrm{kg}^{-1} \cdot \mathrm{h}^{-1}$ & 4.1 & 1.5 \\
\hline Resting metabolic equivalents (METs) & 1.1 & 0.3 \\
\hline Resting HR (beats/min) & 79.6 & 9.8 \\
\hline Age-adjusted HRmax (beats/min) ${ }^{x}$ & 152.7 & 2.7 \\
\hline
\end{tabular}

${ }^{\mathrm{z}}$ Measured by dual-energy $\mathrm{x}$-ray absorptionmetry.

${ }^{\mathrm{y}}$ Measured when the subjects were sitting in a chair for a 5-min.

${ }^{\mathrm{x}}$ Age-adjusted maximum heart rate: $\mathrm{HRmax}=220-$ age in years.

$\mathrm{VO}_{2}=$ oxygen consumption; $\mathrm{HR}=$ heart rate.
Table 3. Metabolic assessment of older Korean adults $(\mathrm{n}=20)$ while performing 15 gardening tasks to determine the exercise intensity involved.

Gardening tasks $\quad$ Mean $^{\mathrm{z}} \quad$ SD

Weeding

METs

$3.4^{\mathrm{bc}} \quad 0.6$

$\mathrm{VO}_{2}\left(\mathrm{~mL} \cdot \mathrm{kg}^{-1} \cdot \mathrm{min}^{-1}\right) \quad 11.8^{\mathrm{bc}} \quad 2.2$

$\mathrm{kj} \cdot \mathrm{kg}^{-1} \cdot \mathrm{h}^{-1}$

$9.0^{\mathrm{abc}} \quad 2.5$

HR (beats/min)

$104.7^{\mathrm{b}}$

13.9

Digging

METs

$\mathrm{VO}_{2}\left(\mathrm{~mL} \cdot \mathrm{kg}^{-1} \cdot \mathrm{min}^{-1}\right)$

$4.5^{\mathrm{a}} \quad 1.2$

$\mathrm{kj} \cdot \mathrm{kg}^{-1} \cdot \mathrm{h}^{-1}$

$15.6^{\mathrm{a}} \quad 4.0$

HR (beats/min)

$10.7^{\mathrm{a}}$

$120.3^{a}$

3.6
18.3

Pruning

METs

$\mathrm{VO}_{2}\left(\mathrm{~mL} \cdot \mathrm{kg}^{-1} \cdot \mathrm{min}^{-1}\right)$

$2.5^{\mathrm{ef}}$

$8.7^{\text {ef }}$

$\mathrm{kj} \cdot \mathrm{kg}^{-1} \cdot \mathrm{h}^{-1}$

HR (beats/min)

Mixing soil

METs

$\mathrm{VO}_{2}\left(\mathrm{~mL} \cdot \mathrm{kg}^{-1} \cdot \mathrm{min}^{-1}\right)$

$\mathrm{kj} \cdot \mathrm{kg}^{-1} \cdot \mathrm{h}^{-1}$

HR (beats/min)

$7.2^{\mathrm{de}}$

$99.9^{\mathrm{bc}}$

0.7

2.3

2.4

13.8

$2.4^{\mathrm{f}}$

$8.4^{\mathrm{f}}$

$6.7^{\mathrm{def}}$

0.7

Filling containers with soil

METs

$\mathrm{VO}_{2}\left(\mathrm{~mL} \cdot \mathrm{kg}^{-1} \cdot \mathrm{min}^{-1}\right)$

$\mathrm{kj} \cdot \mathrm{kg}^{-1} \cdot \mathrm{h}^{-1}$

HR (beats/min)

$103.3^{\mathrm{b}}$

2.3

2.3

16.6

Fertilizing

METs

$\mathrm{VO}_{2}\left(\mathrm{~mL} \cdot \mathrm{kg}^{-1} \cdot \mathrm{min}^{-1}\right)$

$\mathrm{kj} \cdot \mathrm{kg}^{-1} \cdot \mathrm{h}^{-1}$

HR (beats/min)

Raking

METs

$\mathrm{VO}_{2}\left(\mathrm{~mL} \cdot \mathrm{kg}^{-1} \cdot \mathrm{min}^{-1}\right)$

$\mathrm{kj} \cdot \mathrm{kg}^{-1} \cdot \mathrm{h}^{-1}$

HR (beats/min)

Planting transplants

METs

$\mathrm{VO}_{2}\left(\mathrm{~mL} \cdot \mathrm{kg}^{-1} \cdot \mathrm{min}^{-1}\right)$

$\mathrm{kj} \cdot \mathrm{kg}^{-1} \cdot \mathrm{h}^{-1}$

HR (beats/min)

Tying plants to stakes

METs

$\mathrm{VO}_{2}\left(\mathrm{~mL} \cdot \mathrm{kg}^{-1} \cdot \mathrm{min}^{-1}\right)$

$\mathrm{kj} \cdot \mathrm{kg}^{-1} \cdot \mathrm{h}^{-1}$

HR (beats/min)

Sowing seed

METs

$\mathrm{VO}_{2}\left(\mathrm{~mL} \cdot \mathrm{kg}^{-1} \cdot \mathrm{min}^{-1}\right)$

$\mathrm{kj} \cdot \mathrm{kg}^{-1} \cdot \mathrm{h}^{-1}$

HR (beats/min)

Mulching

METs

$\mathrm{VO}_{2}\left(\mathrm{~mL} \cdot \mathrm{kg}^{-1} \cdot \mathrm{min}^{-1}\right)$

$\mathrm{kj} \cdot \mathrm{kg}^{-1} \cdot \mathrm{h}^{-1}$

HR (beats/min)

$\begin{array}{ll}1.8^{\mathrm{g}} & 0.5 \\ 6.1 & \end{array}$

$6.1^{\mathrm{g}} \quad 1.8$

$5.4^{\mathrm{f}} \quad 1.7$

$94.6^{\text {bcd }} \quad 13.9$

$\begin{array}{ll}4.0^{\mathrm{a}} & 0.9\end{array}$

$14.1^{\mathrm{a}} \quad 3.3$

$\begin{array}{ll}7.2^{\mathrm{a}} & 2.4\end{array}$

$104.8^{\mathrm{b}} \quad 15.1$

$3.4^{\mathrm{b}} \quad 0.8$

$12.0^{\mathrm{b}} \quad 2.9$

$9.8^{\mathrm{ab}} \quad 3.6$

$99.6^{\mathrm{bc}} \quad 16.4$

$2.9^{\text {cdef }} \quad 0.9$

$10.0^{\text {cdef }} \quad 3.3$

$8.1^{\text {bcd }} \quad 2.3$

$96.9^{\mathrm{bc}} \quad 14.8$

$3.0^{\text {bcde }} \quad 1.0$

$10.5^{\text {bcde }} \quad 3.4$

$8.3^{\text {bcd }} \quad 2.2$

$97.9^{\mathrm{bc}} \quad 13.6$

$2.7^{\text {ef }} \quad 0.6$

$9.4^{\mathrm{ef}} \quad 2.1$

$8.1^{\text {bcd }} \quad 1.9$

$99.1^{\text {cde }} \quad 12.5$

$3.3^{\text {bcd }} \quad 0.8$

$11.5^{\text {bcd }} \quad 2.8$

$9.4^{\mathrm{abc}} \quad 2.2$

$95.7^{\mathrm{bcd}} \quad 9.3$

Watering using a watering can

METs

$\mathrm{VO}_{2}\left(\mathrm{~mL} \cdot \mathrm{kg}^{-1} \cdot \mathrm{min}^{-1}\right)$

$2.8^{\text {def }}$

$\mathrm{kj} \cdot \mathrm{kg}^{-1} \cdot \mathrm{h}^{-1}$

HR (beats/min)

Watering using a hose

METs

$\mathrm{VO}_{2}\left(\mathrm{~mL} \cdot \mathrm{kg}^{-1} \cdot \mathrm{min}^{-1}\right)$

$\mathrm{kj} \cdot \mathrm{kg}^{-1} \cdot \mathrm{h}^{-1}$

HR (beats/min)

Harvesting produce

METs

$\mathrm{VO}_{2}\left(\mathrm{~mL} \cdot \mathrm{kg}^{-1} \cdot \mathrm{min}^{-1}\right)$

$\mathrm{kj} \cdot \mathrm{kg}^{-1} \cdot \mathrm{h}^{-1}$

HR (beats/min)

$9.8^{\text {def }}$

$7.9^{\mathrm{cd}}$

$99.1^{\mathrm{bc}}$

3.3

2.3

12.5

$2.4^{\mathrm{f}} \quad 0.8$

$8.4^{\mathrm{f}} \quad 2.8$

$7.7^{\mathrm{cd}} \quad 2.3$

$86.5^{\mathrm{de}} \quad 11.1$

$2.7^{\mathrm{ef}} \quad 0.6$

$9.3^{\text {ef }} \quad 1.9$

$8.1^{\text {bcd }} \quad 1.7$

$90.8^{\mathrm{cde}} \quad 10.6$ 
Table 3. (Continued) Metabolic assessment of older Korean adults $(\mathrm{n}=20)$ while performing 15 gardening tasks to determine the exercise intensity involved.

\begin{tabular}{lcc}
\hline Gardening tasks & Mean $^{\mathrm{z}}$ & $\mathrm{SD}$ \\
\hline Washing produce & & \\
$\mathrm{METs}$ & $1.7^{\mathrm{g}}$ & 0.4 \\
$\mathrm{VO}\left(\mathrm{mL} \cdot \mathrm{kg}^{-1} \cdot \mathrm{min}^{-1}\right)$ & $6.0^{\mathrm{g}}$ & 1.5 \\
$\mathrm{kj} \cdot \mathrm{kg}^{-1} \cdot \mathrm{h}^{-1}$ & $5.8^{\mathrm{ef}}$ & 1.3 \\
$\mathrm{HR}($ beats $/ \mathrm{min})$ & $82.8^{\mathrm{e}}$ & 8.7 \\
\hline
\end{tabular}

${ }^{\mathrm{z}}$ Means of metabolic rates for the 15 gardening tasks sharing a common letter are not significantly different by Duncan's multiple range test at $P<0.05$. METs $=$ metabolic equivalents; $\mathrm{VO}_{2}=$ oxygen consumption; $\mathrm{HR}=$ heart rate.

upper body while standing and had lower intensity than the other gardening tasks.

The MET values for some of the gardening tasks in this study corresponded to those previous reported for Americans (Park et al., $2008 \mathrm{~b}$ ) and the MET values for some gardening tasks performed by the older Korean adults were determined. Park et al. (2008b) determined that the exercise intensities of nine gardening tasks such as digging, turning compost, raking, transplanting plants, mulching, hand weeding, mixing soil, filling containers with soil, and transplanting seedlings for American adults (mean age, $77.4 \pm 4.1$ years; mean body mass index, $29.2 \pm 5.4 \mathrm{~kg} /$ $\mathrm{m}^{2}$ ) were low- to moderate-intensity physical activity (1.6-3.6 METs).

Most of the exercise intensities for various gardening tasks in this and the previous study were similar, although tasks such as raking $(2.7 \pm 1.0$ METs $)$, mulching $(2.5 \pm 0.5$ METs $)$, and hand weeding $(2.3 \pm 0.9$ METs $)$ by older Americans (mean age, $77.4 \pm 4.1$ years) displayed a lower intensity than the same tasks performed by older Koreans (mean age, $67.3 \pm$ 2.7 years) in this study (Table 3 ). A gardening task can be performed with different tools (e.g., type, weight), methods, or under different conditions (e.g., compactness of soil, garden size). The variables for gardening methods, environment, and subject characteristics (e.g., age, subject physical fitness) can affect to the exercise intensities of gardening tasks (Gunn et al., 2004, 2005).

Measuring heart rate during steady-state conditions is an indirect way to estimate exercise intensity (Åstrand and Rodahl, 1986). The indirect method is based on a linear relationship between heart rate and $\mathrm{VO}_{2}$ during daily activities, work, or sports. The relationships between the heart rate and $\mathrm{VO}_{2}$ may be different for exercises that engage a large muscle mass compared with exercises using smaller muscle masses (Eston and Brodie, 1986; Vokac et al., 1975) and the kind of exercise (Bhambhami et al., 1997; Collins et al., 1991; Kilbom and Persson, 1981). Many studies have shown that the heart rate and $\mathrm{VO}_{2}$ relationship was modified when using different muscle masses or different modes of exercise (Maas et al., 1989; Rayson et al., 1995; Vokac et al., 1975).

Moderate-intensity gardening tasks included weightbearing motions and used both the upper and lower body. For example, spreading fertilizer on the garden plot $(1 \mathrm{~m} \times$ $1.8 \mathrm{~m}$ ) from a bucket using a shovel followed by mixing it into the soil with a shovel $(1.3 \mathrm{~kg})$ (Table 1) used weightbearing motions and required upper and lower body muscle strength (Restuccio, 1992). A garden exercise program can be developed for physical health benefits that improves muscle strength, flexibility, balance, physical function ability, or bone mineral density. Park et al. (2009) found that active gardeners older than 65 years (mean age, 73 years) who worked in their home garden using moderate-intensity activities for more than 150 min per week had better selfreported physical health than those who were also active but did less gardening. Moreover, daily gardening by Americans (mean age, 72 years) involved moderate-intensity physical activities (3.8 \pm 1.4 METs), which they performed for an average of $33 \mathrm{~h}$ during a typical week in May and $\approx 15 \mathrm{~h}$ a week in June and July (Park et al., 2008c). The older gardeners met the physical activity recommendation of at least $30 \mathrm{~min}$ of moderateintensity physical activity on most days of the week through gardening. Thus, gardening may offer the same physical and psychological benefits (e.g., lower total cholesterol, lower blood pressure, lower mortality, hand function ability, bone mineral density, psychological well-being, and social integration) as non-gardening forms of physical activities (Armstrong, 2000; Park et al., 2009; Reynolds, 1999, 2002; Turner et al., 2002; Walsh et al., 2001).

In conclusion, the MET values of gardening tasks measured in a practical setting should be invaluable when designing garden exercise programs that meet the physical activity requirements for improving or maintaining physical health conditions of older adults. Furthermore, a horticultural therapy program for improving physical functional health conditions in such adults with low levels of physical ability can be designed using gardening tasks of low to moderate intensity.

\section{Literature Cited}

ACSM. 1993. Physical activity, physical fitness, and hypertension. Med. Sci. Sports Exerc. $10: \mathrm{i}-\mathrm{x}$.

ACSM. 1998. Exercise and physical activity for older adults. Med. Sci. Sports Exerc. 30:9921008.

ACSM. 2004. Physical activity and bone health Med. Sci. Sports Exerc. 36:1985-1996.

Ainsworth, B.E., W.L. Haskell, S.D. Herrmann, N. Meckes, D.R. Bassett, Jr., C. Tudor-Locke, J.L. Greer, J. Vezina, M.C. Whitt-Glover, and A.S. Leon. 2011. 2011 compendium of physical activities: A second update of codes and MET values. Med. Sci. Sports Exerc. 43:1575-1581.

Ainsworth, B.E., W.L. Haskell, M.C. Whitt, M.L. Irwin, A.M. Swartz, S.J. Strath, W.L. O’Brien, D.R. Bassett, K.H. Schmitz, P.O. Emplaincourt, D.R. Jacobs, and A.S. Leon. 2000. Compendium of physical activities: An update of activity codes and MET intensities. Med. Sci. Sports Exerc. 32:498-516.

Armstrong, D. 2000. A survey of community gardens in upstate New York: Implications for health promotion and community development. Health Place 6:319-327.

Åstrand, P. and K. Rodahl. 1986. Textbook of work physiology. 3rd Ed. McGraw-Hill, New York, NY.

Bhambhami, Y., S. Buckley, and R. Maikala. 1997. Physiological and biomechanical responses during treadmill walking with graded loads. Eur. J. Appl. Physiol. 76:544-551.

Caspersen, C.J., K.E. Powell, and G.M. Christenson. 1985. Physical activity, exercise, and fitness: Definitions and distinctions for health related research. Public Health Rpt. 100:126-131.

Collins, M.A., K.J. Cureton, D.W. Hill, and C.A. Ray. 1991. Relationship of heart rate to oxygen uptake during weight lifting exercise. Med. Sci. Sports Exerc. 23:636-640.

DiPietro, L. 2001. Physical activity in aging: Changes in patterns and their relationship to health and function. J. Gerontology Ser. A: Biol. Sci. Med. Sci. 56A:13-22.

Doyon, K.H., S. Perrey, D. Abe, and R.L. Hughson. 2001. Field testing of $\mathrm{VO}_{2}$ peak in crosscountry skiers with portable breath-by-breath system. Can. J. Appl. Physiol. 26:1-11.

Eston, R.G. and D.A. Brodie. 1986. Responses to arm and leg ergometry. Brit. J. Sports Med. 20: 4-6.

Galloway, M.T. and P. Jok1. 2000. Aging successfully: The importance of physical activity in maintaining health and function. J. Amer. Acad. Orthop. Surg. 8:37-44.

Gunn, S.M., A.G. Brooks, R.T. Withers, C.J. Gore, J.L. Plummer, and J. Cormack. 2005. The energy cost of household and garden activities in 55 to 5 year old males. Eur. J. Appl. Physiol. 94:476-486.

Gunn, S.M., G.E. van der Ploeg, R.T. Withers, C.J. Gore, N. Owen, A.E. Bauman, and J. Cormack. 2004. Measurement and prediction of energy expenditure in males during household and garden tasks. Eur. J. Appl. Physiol. 91:61-70.

Hui, E.K. and L.Z. Rubenstein. 2006. Promoting physical activity and exercise in older adults. J. Amer. Med. Directors Assn. 7:310-314.

Kawakami, Y., D. Nozaki, A. Matsuo, and T. Fukunaga. 1992. Reliability of measurement of oxygen uptake by a portable telemetric system. Eur. J. Appl. Physiol. 65:409-414.

Kilbom, A. and J. Persson. 1981. Cardiovascular response to combined dynamic and static exercise. Circ. Res. 48:93-97.

Lee, I., R.S. Paffenbarger, and C. Hsieh. 1991. Physical activity and risk of developing colorectal cancer among college alumni. J. Natl. Cancer Inst. 83:1324-1329.

Maas, S., M.L.J. Kok, H.H. Westra, and H.C.G Kemper. 1989. The validity of the use of heart rate in estimating oxygen consumption in static and combined static/dynamic exercise. Ergonomics 32:141-148.

McArdle, W.D., F.L. Katch, and V.L. Katch. 2007. Exercise physiology: Energy, nutrition, and human performance. Lippincott Williams \& Wilkins, Philadelphia, PA.

McLaughlin, J.E., G.A. King, E.T. Howley, D.R. Bassett, Jr., and B.E. Ainsworth. 2001. Validation of the Cosmed $\mathrm{K} 4 \mathrm{~b}^{2}$ portable metabolic system. Intl. J. Sports Med. 22:280-284.

Nelson, M.E., W.J. Rejeski, S.N. Blair, P.W. Duncan, J.O. Judge, A.C. King, C.A. Macera, and C. Castaneda-Sceppa. 2007. Physical activity and public health in older adults. Recommendation from the American College of Sports Medicine and the American Heart Association. Med. Sci. Sports Exerc. 39:1435-1445.

Norton, K., L. Norton, and D. Sadgrove. 2010. Position statement on physical activity and 
exercise intensity terminology. J. Sci. Med. Sport 13:496-502.

Park, S.A., C.A. Shoemaker, and M.D. Haub. 2008a. How to measure exercise intensity of gardening tasks as a physical activity for older adults using metabolic equivalents. Acta Hort. 775:37-40.

Park, S.A., C.A. Shoemaker, and M.D. Haub. 2008b. A preliminary investigation on exercise intensities of gardening tasks in older adults. Percept. Mot. Skills 107:974-980.

Park, S.A., C.A. Shoemaker, and M.D. Haub. 2008c. Can older gardeners meet the physical activity recommendation through gardening? HortTechnology 18:639-643.

Park, S.A., C.A. Shoemaker, and M.D. Haub. 2009. Physical and psychological health conditions of older adults classified as gardeners or nongardeners. HortScience 44:206-210.

Pate, R.R., M. Pratt, S.N. Blair, W.L. Haskell, C.A. Macera, C. Bouchard, D. Buchner, W. Ettinger, G.W. Heath, A.C. King, A. Kriska, A.S. Leon, B.H. Marcus, J. Morris, R.S. Paffenbarger, K. Patrick, M.L. Pollock, J.M. Rippe, J. Sallis, and
J.H. Wilmore. 1995. A recommendation from the Centers for Disease Control and Prevention and the American College of Sports Medicine. J. Amer. Med. Assn. 273:402-407.

Powell, K.E., P.D. Thompson, C.J. Casperson, and J.S. Kendrick. 1987. Physical activity and the incidence of coronary heart disease. Annu. Rev. Public Health 8:253-287.

Rayson, M.P., A. Davies, D.G. Bell, and E.S. Rhodes-James. 1995. Heart rate and oxygen uptake relationship: A comparison of loaded marching and running in women. Eur. J. Appl. Physiol. 71:405-408.

Restuccio, J.P. 1992. Fitness the dynamic gardening way. Balance of Nature Publishing, Cordova, TN.

Reynolds, V. 1999. The Green Gym: An evaluation of a pilot project in Sonning Common, Oxfordshire, Report no. 8. Oxford Brookes University, Oxford, UK.

Reynolds, V. 2002. Well-being comes naturally: An evaluation of the BTCV Green Gym at Portslade, East Sussex, Report no. 17. Oxford Brookes University, Oxford, UK.
Turner, L.W., M.A. Bass, L. Ting, and B. Brown. 2002. Influence of yard work and weight training on bone mineral density among older U.S. women. J. Women Aging 14:139-149.

U.S. Department of Health and Human Services. 1996. Physical activity and health: A report of the surgeon general. U.S. Department of Health and Human Services, Centers for Disease Control and Prevention, National Center for Chronic Disease Prevention and Health Promotion, The President's Council on Physical Fitness and Sports, Atlanta, GA, p. 13-14. Disease Control and Prevention, National Center for Chronic Disease Prevention and Health Promotion, The President's Council on Physical Fitness and Sports, Atlanta, GA.

Vokac, Z., H. Bell, E. Bautz-Holter, and K. Rodahl. 1975. Oxygen uptake/heart rate relationship in leg and arm exercise, sitting and standing. J. Appl. Physiol. 39:54-59.

Walsh, J.M.E., A.R. Pressman, J.A. Cauley, and W.S. Browner. 2001. Predictors of physical activity in community-dwelling elderly white women. J. Gen. Intern. Med. 16:721-727. 